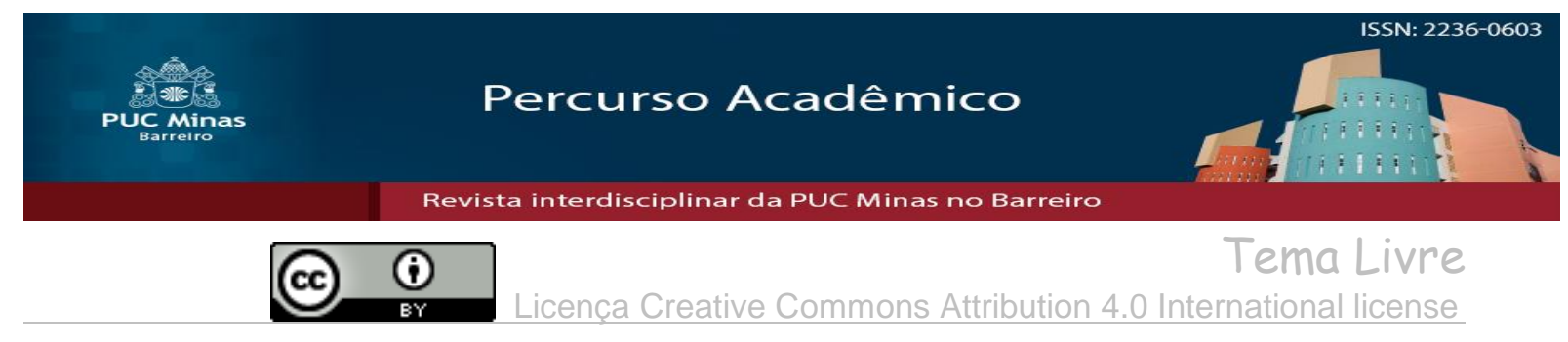

\title{
Processo de regularização de moradias: \\ levantamento topográfico e processamento dos dados - Região do Barreiro
}

\author{
Housing regularization process: \\ topographic survey and data processing - Barreiro Region
}

\author{
Dayana Corrêa de Oliveira ${ }^{1}$ \\ Bruna Soares Silva ${ }^{1}$ \\ Sílvia Carolina Martins Braga Maciel$^{2}$ \\ Everaldo Bonaldo ${ }^{3}$ \\ Aline de Araújo Nunes ${ }^{4}$
}

\section{Resumo}

A extensão universitária é responsável por um conjunto de práticas inter e multidisciplinares. O projeto "A Engenharia e a Rede Social do Barreiro: tecnologia social a serviço da comunidade", desenvolvido principalmente por alunos do curso de Engenharia Civil, da Pontifícia Universidade Católica de Minas Gerais - Unidade Barreiro, tem o propósito de atender as demandas solicitadas pelos moradores da região do Barreiro, relativas à regularização de moradias e introduzir o estudante à realidade que o cerca, promovendo o desenvolvimento dos saberes teóricos aliados a prática. Sabe-se que, obter um imóvel regularizado, pode ser por vezes, uma tarefa complexa que requer investimentos e tempo, elementos que o cidadão muitas vezes não possui. $\mathrm{O}$ presente artigo tem como objetivo explanar as etapas do referido projeto de extensão, tais como, levantamento de dados topográficos, processo cadastral e memorial descritivo, que são realizados na comunidade da região para alcançar a regularização da moradia.

Palavras-chave: Regularização fundiária. Comunidade. Topografia. Planta cadastral. Memorial descritivo.

\begin{abstract}
The university extension is responsible for a set of inter and multidisciplinary practices. The project "The Engineering and Social Network of Barreiro: social technology at the service of the community", developed mainly by students of the Civil Engineering course of the Pontifical Catholic University of Minas Gerais - Barreiro Unit, has the purpose of meeting the demands requested by the residents of the region of Barreiro, regarding the regularization of housing and introduce the student to the reality that surrounds it, promoting the development of theoretical knowledge allied to practice. It is known that obtaining a property regularized can sometimes be a complex task that requires investments and time, elements that the citizen often does not own. The objective of this article is to explain the stages of this extension project, such as survey of topographic data, cadastral process and descriptive memorial, which are carried out in the community of the region to achieve the regularization of housing.
\end{abstract}

Artigo recebido em 11 de Novembro de 2017 e aprovado em 10 de Abril de 2019

${ }^{1}$ Graduandas de Engenharia Civil. PUC Minas, Unidade Barreiro, 2017. Belo Horizonte - MG, Brasil.

E-mail: dayana.correa@sga.pucminas.bre bruna.silva.888715@sga.pucminas.br

${ }^{2}$ Professora Msc. do Departamento de Engenharia Civil - PUC Minas - Barreiro, Belo Horizonte - MG, Brasil. E-mail: silviacmbraga@gmail.com

${ }^{3}$ Coordenador do projeto de extensão - A engenharia e a rede social do Barreiro: tecnologia social a serviço da Comunidade. Departamento de Engenharia Civil - PUC Minas - Barreiro, Belo Horizonte MG, Brasil. E-mail: bonaldo@pucminas.br.

${ }^{4}$ Coordenadora de extensão do curso de Engenharia Civil - PUC Minas - Barreiro, Belo Horizonte MG, Brasil. E-mail: alineanunes@pucminas.br 
Key-words: Land regularization. Community. Topography. Cadastral plant. Descriptive memorial.

\title{
Introdução
}

Conforme Hennington (2005, p. 256), a Constituição Federal Brasileira distingue a educação como um direito legal do cidadão. Tanto que, no artigo 207 desta consta "[...] que as universidades gozam de autonomia didático-científica, administrativa e de gestão financeira e patrimonial, e obedecerão ao princípio da indissociabilidade entre ensino, pesquisa e extensão." Dado que, a Universidade é considerada uma instituição que tem por objetivo o desenvolvimento de pessoas a partir de três pilares ensino, pesquisa e extensão.

Neste contexto é possível dizer que a extensão de um modo geral atua de maneira significativa quando idealizada por meio de intervenções sociais, visto que:

\begin{abstract}
A dimensão cultural remete a várias espécies de valor - histórico, afetivo, epistemológico, paisagístico, urbanístico e científico —, atribuídas aos assentamentos. Como essa dimensão corresponde ao que jamais pode ser reproduzido ou substituído sem perdas, cada assentamento detém sua própria história de formação dos valores culturais - luta pela permanência, convívio social etc. - , ou, por outra, cada uma presa um passado culturalmente construído, cuja função é o reforço contínuo da sua identidade social (GONÇALVES e ZANCHETI, 2014, p. 325).
\end{abstract}

À medida que o conhecimento se estende para além da sala de aula, via práticas extensionistas ou de pesquisa, ela proporciona ao aluno uma leitura da realidade empírica, a problematização e a busca de respostas inovadoras e condizentes com as singularidades das experiências vividas. Isso se traduz ainda em importante meio de oxigenação dos projetos pedagógicos, que devem ser continuamente alimentados pelos problemas que a realidade coloca, o que pode resultar no reconhecimento de novas competências que se apresentam em face das mudanças na esfera da vida social e econômica (PONTIFÍCIA UNIVERSIDADE CATÓLICA DE MINAS GERAIS, p.63, 2011).

A extensão, associada ao ensino e a pesquisa, cumpre seu papel de capacitar o futuro profissional a atuar de forma científica e técnica, com forte profissionalismo e responsabilidade em sua área. Isso evidencia o trabalho construído diariamente na PUC Minas para manter a indissociabilidade entre o ensino, a extensão e a pesquisa.

Conforme Paiva, p.9 (2012):

A regularização fundiária consiste no conjunto de medidas jurídicas, urbanísticas, ambientais e sociais que visam à regularização de assentamentos irregulares e à titulação de seus ocupantes, de modo a garantir o direito social à moradia, o pleno desenvolvimento das funções sociais da propriedade urbana e o direito ao meio ambiente ecologicamente equilibrado (Lei no 11.977/2009, art. 46). 
Segundo Brasil (2013), com o intuito de estabelecer o direito à moradia, em concordância com as leis urbanas e de proteção ao meio ambiente, à legislação, a Lei acima citada assegura a legalização para ocupações de baixa renda no processo de regularização fundiária. De modo geral, o processo fundiário brasileiro procura alternativas que permitam às famílias ter acesso às condições básicas de infraestrutura, habitação, serviços e equipamentos públicos.

Assim, o projeto de extensão denominado, "A Engenharia e a Rede Social do Barreiro: tecnologia social a serviço da comunidade", realizado principalmente por extensionistas do curso de Engenharia Civil da Unidade Barreiro, contribui durante anos para a regularização de moradias e o empoderamento das famílias de forma social e gratuita, através da participação e comprometimento de alunos e professores envolvidos na realização das práticas topográficas, bem como o levantamento topográfico das moradias/edificações e nos processamentos dos dados obtidos no campo conforme descrito neste artigo.

\section{Metodologia do projeto sob a ótica do extensionista}

\subsection{Contextualização do projeto}

No início do semestre foi realizada a apresentação do projeto aos alunos, a fim de divulgar o programa de extensão e selecionar os alunos extensionistas.

Posteriormente foram identificados e selecionados os beneficiários principalmente através das reuniões da Rede Social e com os moradores da Regional Barreiro, por meio das demandas apresentadas e que foram utilizadas para o planejamento das atividades do semestre.

A capacitação dos extensionistas e professores foi efetuada no decorrer das práticas através de treinamentos e oficinas promovidas pela PROEX - Pró-Reitoria de Extensão, os quais são treinados de acordo com a proposta do projeto.

Após a conclusão de tais etapas, foram realizadas reuniões entre o corpo docente apoiador do projeto e os alunos selecionados, de maneira a agrupar e orientar os extensionistas em grupos pré-estabelecidos de modo que as demandas fossem atendidas da melhor forma possível.

Uma vez identificadas as demandas, os grupos realizaram visitas sob a supervisão dos professores nas áreas previamente selecionadas, prioritariamente na Regional Barreiro, para identificação das irregularidades inicialmente relatadas.

Nesta etapa do projeto os solicitantes foram orientados pelo Serviço de Assistência Jurídica (SAJ - PUC Minas) a identificar junto à prefeitura os processos necessários para a regularização das moradias.

Posteriormente, os alunos acompanhados de um professor foram a campo para efetuar as medições necessárias relativas à parte topográfica e/ou arquitetônica. 
As práticas extensionistas desenvolvidas ao longo do semestre foram determinadas basicamente pelo levantamento topográfico dos lotes que compreendem os itens abaixo.

\subsection{Levantamento topográfico com auxílio de Estação Total}

As regularizações de moradias encaminhadas ao projeto de extensão "A Engenharia e a Rede Social do Barreiro: Tecnologia Social a Serviço da Comunidade", que necessitaram de levantamento de dados topográficos, foram atendidas por grupos de alunos, orientados por professores.

Os alunos que participaram das visitas às moradias atendidas, também foram orientados a fazer o registro fotográfico (Figura 1) e o esboço geral da propriedade e logradouros que estavam próximos ao lote em estudo, para melhor localização dos pontos cadastrados ao efetuar o desenho topográfico.

\section{Figura 1: Registro fotográfico do imóvel}
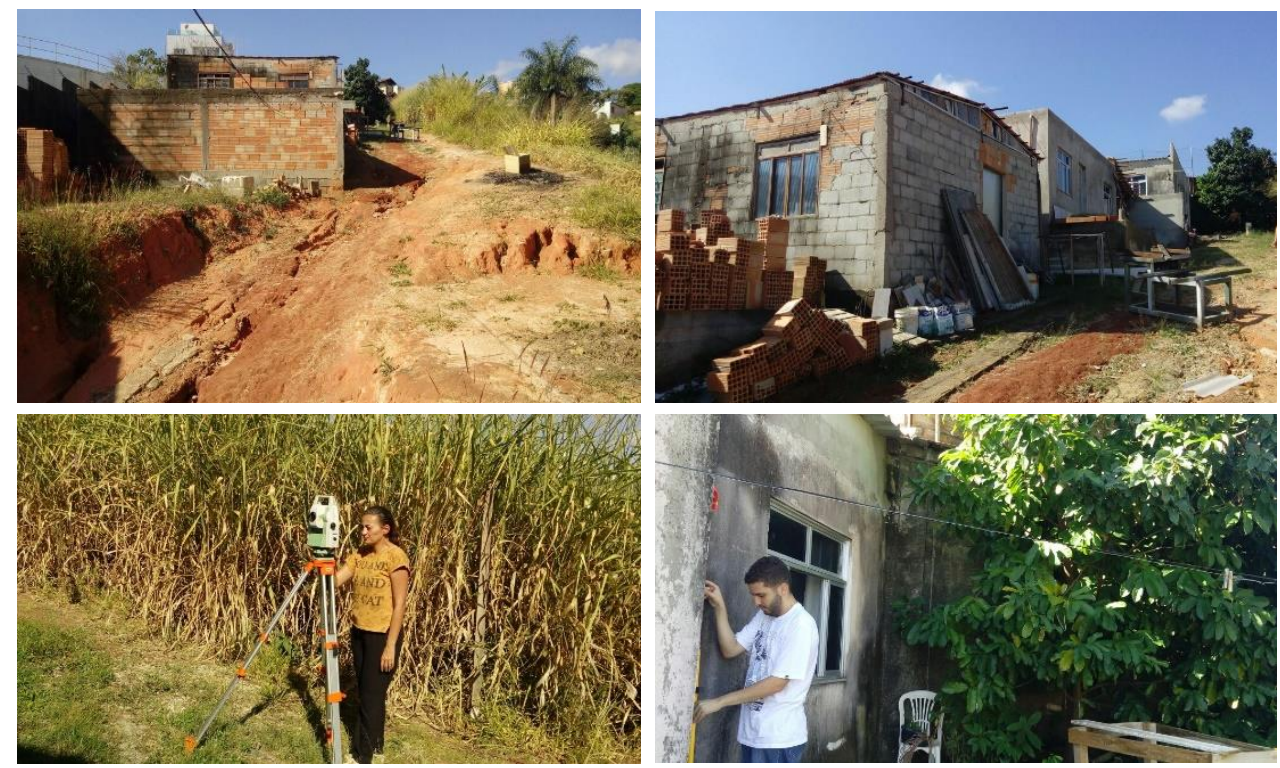

Fonte: (ARQUIVO DOS AUTORES, 2017).

É importante salientar que a base principal dos dados de campo foi coletada com o auxílio de equipamentos de topografia, tais como, Estação Total (LEICA TS02), trenas a laser (GLM80), trena de fibra de vidro de $20 \mathrm{~m}$, prisma dotado de bastão com altura máxima de $3 \mathrm{~m}$, tripés com travas e base para nivelar a Estação Total, sendo estes disponibilizados pela PUC Minas - Unidade Barreiro no laboratório de topografia.

O método adotado para levantamento topográfico foi o planialtimétrico, que considera leituras de distâncias horizontais, ângulos e alturas coletadas de forma direta com o auxílio do equipamento de medição conhecido por Estação Total que é preciso e rápido nas coletas de dados. A poligonal topográfica, parte importante do levantamento é definida dentro do perímetro o qual é realizado o cadastro dos pontos com a finalidade de ser a base para a evolução do trabalho (TULER e SARAIVA 2014, p.187). 
É essencial ressaltar que em alguns casos a evolução dos trabalhos foi interrompida, pois foram percebidos pontos inacessíveis nos imóveis e no momento as ferramentas disponíveis não foram ideais para a realização da coleta dos dados. No caso destes serviços, seriam necessários o uso de instrumentos mais sofisticados como, por exemplo, GPS tipo RTK (Real Time Kinematic), que é a atual tecnologia desenvolvida no âmbito do geoprocessamento e muito utilizada na área de topografia para a coleta de dados em tempo real, uma vez que o operador do sistema obtém informações diretas do campo sem a necessidade de pós-processamento dos dados de forma rápida e com alta precisão.

\subsection{Processamento dos dados coletados em campo}

Uma das partes importantes deste trabalho foi o processamento dos dados planialtimétricos no software Bentley topoGRAPH versão 08.11.09.205, que está disponível nos laboratórios da PUC Minas.

O processamento dos dados coletados durante as visitas foi realizado no Laboratório de Topografia da PUC Minas - Unidade Barreiro.

No laboratório os pontos foram devidamente descarregados da Estação Total para o topoGRAPH, onde foram calculadas a poligonal (tipo aberta ou fechada), os pontos irradiados, carregado o desenho e exportado para o AutoCAD 2017 na versão estudante.

Em seguida os pontos foram interligados no software AutoCAD para obtenção da planta topográfica (Figura 2).

Figura 2: Exemplo de planta topográfica com nuvem de pontos coletados

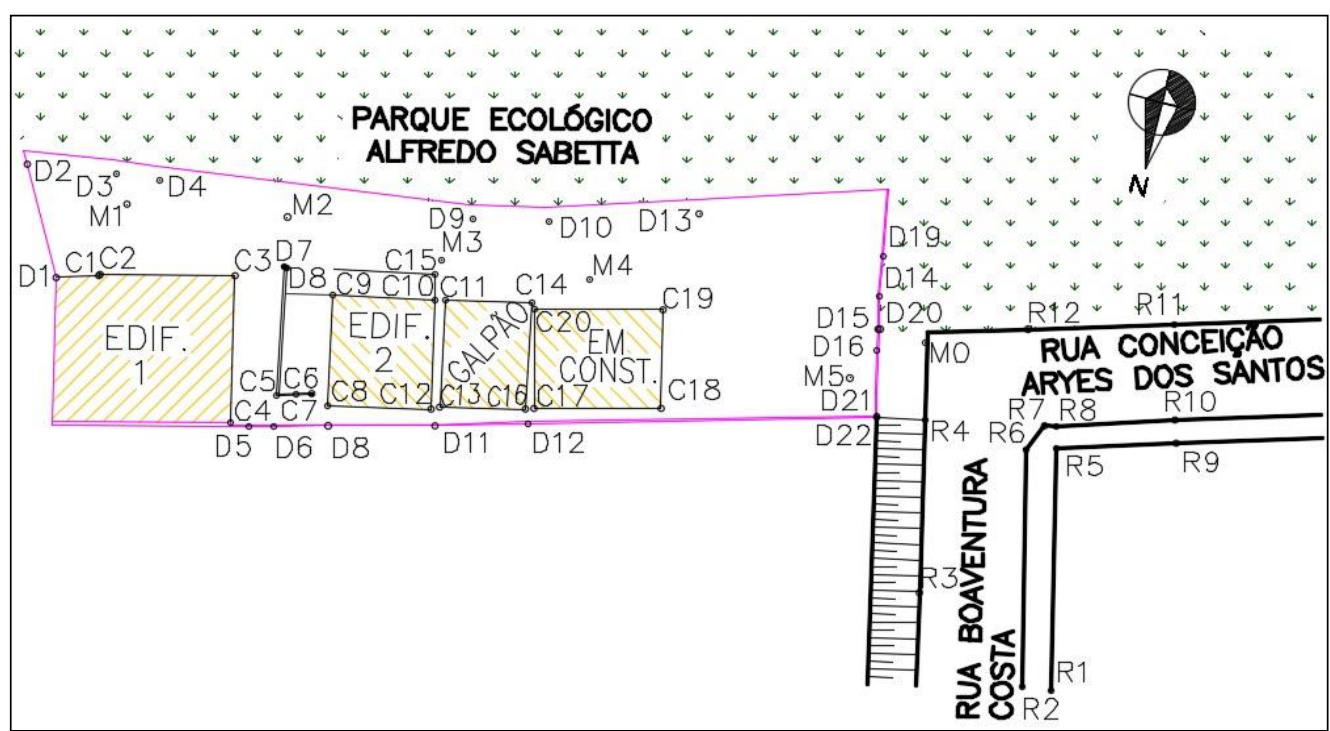

Fonte: (ARQUIVO DOS AUTORES, 2017). 


\subsection{Confecção das plantas topográficas cadastrais}

As plantas de situação e localização foram elaboradas na ferramenta de trabalho AutoCAD 2017 e para garantia do seu georreferenciamento, alguns recursos foram utilizados, tais como, consultas no site da Prefeitura Municipal de Belo Horizonte às plantas de parcelamento de solo, CP (PLANTAS ONLINE, 2017) e imagens disponíveis no sistema online de dados cadastrais geográfico da cidade de Belo Horizonte (GEOSIURBE, 2017), com o intuito também, de melhor entendimento da área analisada.

Com os pontos advindos da topografia interligados e inseridas as plantas $\mathrm{CP}$ e imagem GEOSIURBE, no software AutoCAD, foi possível realizar a confecção das plantas de situação e localização que foram feitas respectivamente na escala de 1:250 ou 1:500 (Figura 3) e 1:1000 (Figura 4).

Figura 3: Exemplo de planta de situação elaborada

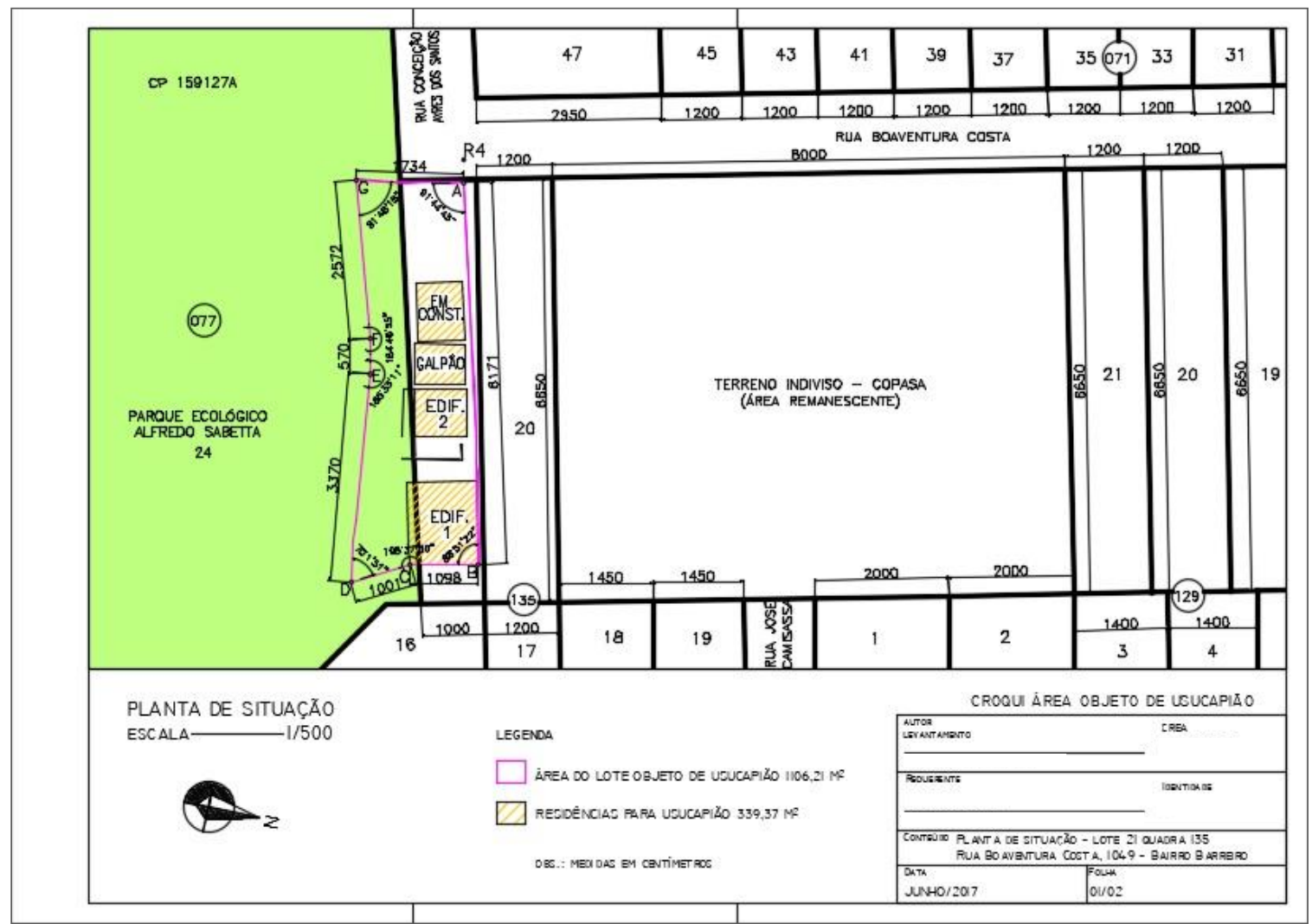

Fonte: (ARQUIVO DOS AUTORES, 2017).

\subsection{Memorial descritivo da propriedade}

Os memoriais descritivos dos imóveis visitados foram realizados seguindo as recomendações da Associação Brasileira de Normas Técnicas - NBR 13.133 (1994), que fixa as condições para execução dos vários tipos de levantamentos, dentre eles o 
levantamento topográfico planialtimétrico, onde ressalta-se a necessidade de elaboração do memorial descritivo da propriedade.

O memorial descritivo como o nome sugere, é um documento que consta a descrição detalhada da propriedade e suas edificações (caso exista), para fins judiciais.

Este tipo de registro contém principalmente:

a) dados de identificação do proprietário;

b) dados de identificação do lote;

c) imagem do Google Earth Online processada no software AutoCAD Civil 3D 2018 demonstrando a localização geográfica do lote e logradouros;

d) tipo de residência;

e) identificação dos confrontantes (vizinhos);

f) descrição detalhada do lote.

Por fim, os documentos que foram gerados e/ou utilizados durante os trabalhos - imagem da planta CP, imagem GEOSIURBE, plantas de situação e localização nas extensões "dwg e pdf" e o memorial descritivo em "doc" - são gravados em um CD, que foi posteriormente entregue ao responsável por enviá-lo juntamente com as plantas e relatórios impressos pertinentes ao imóvel ao solicitante da regularização.

\section{Resultados}

\subsection{Plantas topográficas cadastrais e memorial descritivo}

A partir do processamento de dados topográficos foram gerados produtos gráficos que constituem o Memorial Descritivo. Tais produtos que caracterizam a propriedade são as plantas de situação e localização (Figura 4), que identificam uma das propriedades atendidas pelo projeto durante o ano de 2017.

Figura 4: Exemplo de planta de localização elaborada

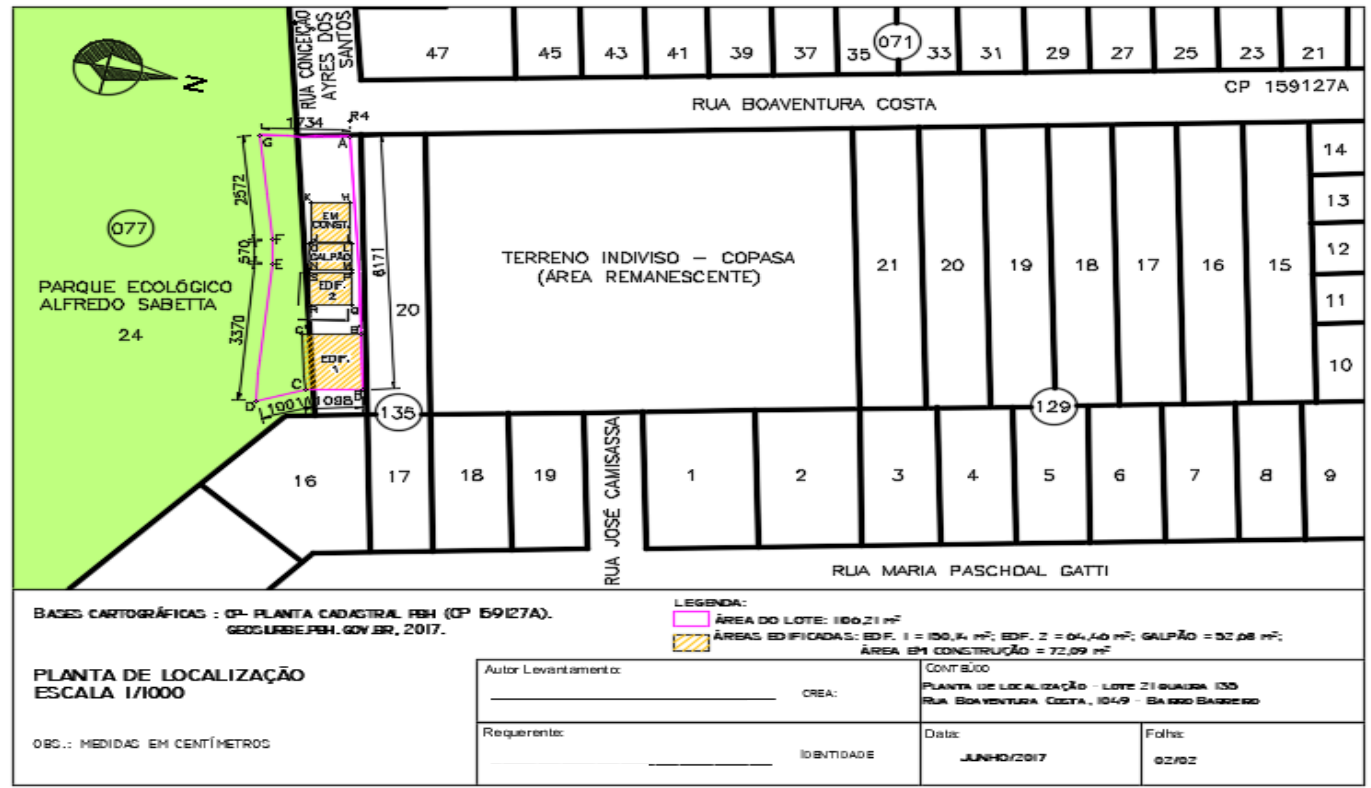

Fonte: (ARQUIVO DOS AUTORES, 2017). 
Em sequência, com base nos dados apresentados nas plantas o resultado obtido foi o registro do imóvel detalhado de modo a descrever minunciosamente as características da propriedade contendo os dados do proprietário e seus confrontantes.

Nesse contexto, é importante evidenciar que durante o ano de 2017, o projeto não se limitou a atender somente a esta demanda (Figura 3 e 4), o mesmo também beneficiou com trabalhos topográficos e projetos arquitetônicos gratuitos um total de 10 moradias que necessitavam ou estavam em processo de regularização.

\subsection{Portfólio do trabalho de extensão}

Durante a execução dos trabalhos, os grupos de extensionistas realizam a criação de um portfólio, onde constam atas dos encontros, informando:

g) o que foi realizado;

h) os materiais utilizados;

i) desafios encontrados;

j) extensionistas presentes;

k) croquis feitos durante as visitas;

1) cópia das plantas de localização e situação finalizadas;

m) comentário final dos integrantes do grupo sobre sua participação na execução da demanda (opcional).

Ao finalizar a demanda, o líder de cada grupo entrega o portfólio à Pró-Reitoria de Extensão como documento comprobatório das atividades realizadas no semestre, e também para arquivamento dos trabalhos realizados no semestre.

\section{Considerações finais}

Nota-se que a extensão universitária é uma maneira de auxiliar a sociedade de forma prática e eficiente nos problemas que envolvam os direitos e deveres dos cidadãos. Ela incentiva seus integrantes (docentes, discentes, corpo técnicoadministrativo) na participação em questões relativas ao processo de crescimento sócio comunitário.

As intervenções realizadas por este projeto de extensão são um mecanismo importante de comunicação com a comunidade, pois a execução das etapas técnicas, tais como, levantamento topográfico, processamento dos dados coletados em campo, elaboração e confecção das plantas topográficas cadastrais: de situação e localização e o memorial descritivo, possibilitam que o morador com os documentos em mãos (plantas e memorial), siga com o processo de regularização de sua moradia junto à prefeitura, conforme orientação do SAJ/PUC. É necessário ressaltar que o projeto: "A Engenharia e a Rede Social do Barreiro: tecnologia social a serviço da comunidade", além de efetuar regularizações de moradias, recebe também outras demandas no âmbito da Engenharia Civil. 
As práticas extensionistas, são um importante instrumento para a integração da instituição de ensino e os alunos com a sociedade aos arredores, sendo que o benefício adquirido é mútuo para ambas as partes, uma vez que o projeto promove a interdisciplinaridade e interação dos alunos com a sociedade que o cerca, favorecendo não somente a formação técnica, mas social, ética e possibilita ampliar seus conhecimentos relativos às atividades específicas da Engenharia Civil.

Assim, é possível compreender a importância dos procedimentos legais adotados para os processos de regularização de moradias e o empoderamento das famílias de forma gratuita e social.

\section{Referências}

ASSOCIAÇÃO BRASILEIRA DE NORMAS TÉCNICAS. NBR 13133 - Execução de levantamento topográfico: elaboração. Rio de Janeiro: ABNT, 1994.

BRASIL. Ministério das Cidades. Regularização Fundiária Urbana: como aplicar a Lei Federal no 11.977/2009 - Ministério das Cidades. 2013. 56f. Secretaria Nacional de Acessibilidade e Programas Urbanos e Secretaria Nacional de Habitação, Brasília, 2013.

GEOSIURBE. SIURBE-BHMap (online). Belo Horizonte. Disponível em: <http://geosiurbe.pbh.gov.br/webmap/>. Acesso em: 16 nov. 2017.

GONÇALVES, Norma Lacerda; ZANCHETI, Sílvio Mendes. Conservação urbana e regularização fundiária de assentamentos populares. Revista Brasileira de Gestão Urbana, v. 6, n. 3, p.323-337, set/dez. 2014.

HENNINGTON, Élida Azevedo. Acolhimento como prática interdisciplinar num programa de extensão universitária. Cad. Saúde Pública, Rio de Janeiro, v. 21, n. 1, p.256-265, jan/fev. 2005.

PAIVA, João Pedro Lamana. Regularização fundiária de interesse social. São Paulo. Coleção Cadernos: IRIB, 2012.

PLANTAS ONLINE. Consultas a plantas de parcelamento do solo (CP). Belo Horizonte. Disponível em: <http://portal5.pbh.gov.br/plantacp/inicio.do>. Acesso em: 16 nov. 2017.

PONTIFÍCIA UNIVERSIDADE CATÓLICA DE MINAS GERAIS. Plano de Desenvolvimento Institucional (PDI) 2012 a 2016. Belo Horizonte, 2011.

TULER, Marcelo; SARAIVA, Sérgio. Fundamentos de topografia. Belo Horizonte: Bookman, 2014. 